\title{
The Agile Artifact - an Antifragile Approach to Design and Innovation
}

\author{
Jan Eckert \\ Department of Arts and Design, Lucerne University of Applied Sciences and Arts, Switzerland
}

Copyright $\bigcirc 2017$ by authors, all rights reserved. Authors agree that this article remains permanently open access under the terms of the Creative Commons Attribution License 4.0 International License

\begin{abstract}
In this paper, two hypotheses introduce into the question whether incompleteness as an approach to designing artefacts might lead to a better involvement of the artefact's future users and act as a trigger for future innovation. The first hypothesis introduces the concept of Handlungsspielraum which focuses the definition and incompleteness of an artefact in its context. The second picks up Nassim Nicholas Taleb's concept of Antifragility, which embraces uncertainty as an integral part of any (innovation) process. The two hypotheses are illustrated by the comparison of two motorcycle manufacturers, both providing their products with a different attitude towards openness. As a conclusion, the concept of the Agile artefact is introduced. The Agile Artefact fosters an artefact's continuous mutation and improvement by embracing both hypotheses: incompleteness as trigger for innovation and the Antifragile as strategy to embrace the uncertain and overcome crises.
\end{abstract}

Keywords Agile Artifact, Antifragile, Incompleteness, Open Design, Open Innovation

\section{Introduction}

Even if the idea of designing in iterative episodes is not new to innovation processes, in the design domain Participatory Design [1], Co-creation [2], Open Design [3] and the Maker movement [4] represent rather recent frameworks and have broken up former linear or author-driven approaches by incorporating iterative and collaborative design cycles into the overall (innovation) process. A common issue regarding most of these approaches' outcomes and products though is that even if developed within an open and iterative framework, most of the openness ends abruptly, once the artefact is finished or the product is launched. The reason of this abrupt end mostly is tied to the definition and completeness of the artefact - a state, which doesn't allow further negotiation about an artefact's future use, modification or improvement.

In this paper, two hypotheses are stressing the question, whether as an alternative to the complete and closed, designing the incomplete might lead to continue the innovation process and work as a trigger for future interpretations and modifications of the artefact. The first hypothesis is based upon the concept of Handlungsspielraum [5] - a framework which focuses the definition and (in) completeness of an artefact in its context. The second hypothesis questions, whether the antifragile [6], a concept coined by philosopher Nassim Nicholas Taleb, might be transferred to design processes and whether its inclusion of the uncertain might result in a higher potential for innovation.

The hypotheses are illustrated by the comparison of two motorcycle manufacturers, both delivering the same product but with a fundamental difference regarding their attitude towards openness. As a conclusion, the model of the Agile artefact [7] will be introduced by embracing both hypotheses, incompleteness as trigger for innovation and the antifragile as strategy to embrace the uncertain and overcome crises. Overall goal of this paper is to introduce the model of The Agile Artefact as an approach of how the incomplete might trigger a continuous innovation process based upon the inclusion of future participants by the proposal of the stage a conceptual gap or space in the artefact's design.

\section{First Hypothesis: Incompleteness as a Trigger for Innovation}

The first hypothesis considers that Open Innovation and Open Design should tend to generate outputs, which are characterized by a certain degree of incompleteness. This incompleteness turns into a quality at the point when the artefact start offering users a higher potential of being modified and re-interpreted compared to finished products. Consequently, incompleteness should imply a higher potential for innovation. At the same time the main quality of a product shifts from its final definition towards its openness 
for re-interpretation, improvement and mutation. Following this hypothesis, the question rises how incompleteness might be incorporated into the design process and the design of the artefact itself.

A first approach towards answering this question is made by the concept of Handlungsspielraum (HSR) [5], which refers to critic Umberto Eco's "Opera Aperta" [8], Roger Callois" "Les Jeux et les hommes" [9] and the rather well-known concept of Affordances [10-12]. At its core stand artefacts that are characterized by incompleteness. This incompleteness may be a conceptual gap, a low-defined functional approach or an aesthetical trigger of incompleteness. Aim of these triggers is to open a conceptual space where people's interpretations or further mutations of the artefact and its use may unfold. While in English the word Handlungsspielraum could be best translated by Latitude, the German word (German: Handlung = action; Spiel $=$ play/game; Raum $=$ space/range $)$ includes two important aspects, which stand at the core of HSR. One is the double meaning of Spiel/play, since it can mean play a game, or also describes a little space or gap, which allows a mechanism to move (e.g. a bolt has a little play). The other is Raum/space which extends the artefact itself to the context and conceptual space it is being used in.

In design, the most commonly known concept HSR is referring to, is the concept of Affordances claimed by psychologists James Gibson and Donald Norman [10-12]. While Affordances often are described as an invitation or "way to access a range of possibilities to act" [13: p.114], $H S R$ extends this invitation by including the artefact's mutation and re-interpretation. In his definition of the Interface and "Interaktionsraum" [13: p.155] (tr. Interaction-space), designer Gui Bonsiepe describes such a space, where the user's actions emerge (Fig. 1) - or in sociologist Herbert Simon's words "a meeting point (...) between an 'inner' environment, the substance and organization of the artefact itself, and an 'outer' environment, the surroundings in which it operates. " [14: p.6]. While the actions in his model mainly refer to the information that is provided by the artefact itself, HSR extends the Interaction-space by considering all contextual information, as well as the user's deliberate interpretation and mutation of the artefact. Thus, besides the intended use and interaction, $H S R$ includes also non-intended [15-16] or playful interactions.

While the original model of HSR emerges from six aspects (Fig. 2), for a better understanding, in this paper a simplified model will be used (Fig. 3). It focuses the constraints provided by the artefact and the range of action provided by the context the artefact is used in.

The way interaction and play unfold within $H S R$ can be described in two episodes (Fig. 4). In the first one called negotiating episode, a low-definition artefact provides a low level of constraints (e.g. prototype) and therefore embeds easily into a variety of contexts. One might say: in this episode, the artefact is a proposal whose definition or use may be negotiated by the user in a chosen context.

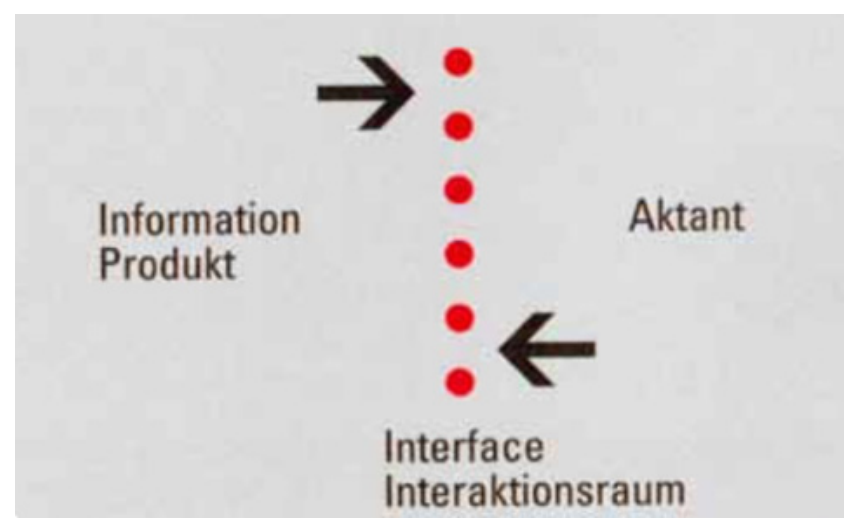

Figure 1. Interface and Interaktionsraum, Bonsiepe2009

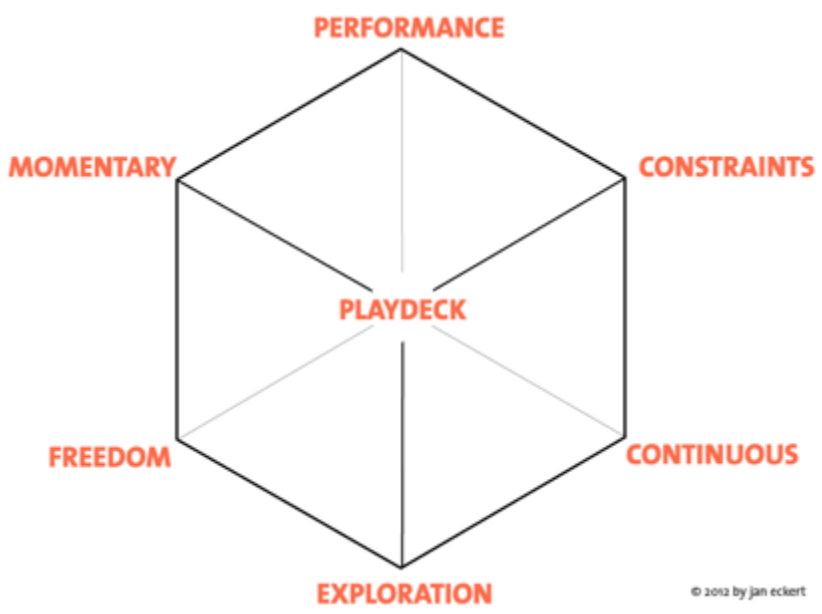

Figure 2. Six aspects of Handlungsspielraum, Eckert, J. 2012

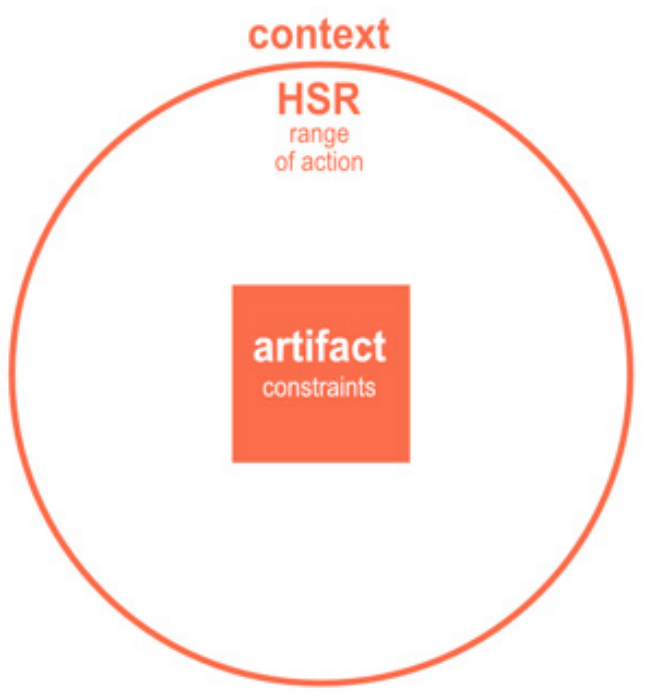

Figure 3. The artefact and range of action, Eckert, J. 2017 

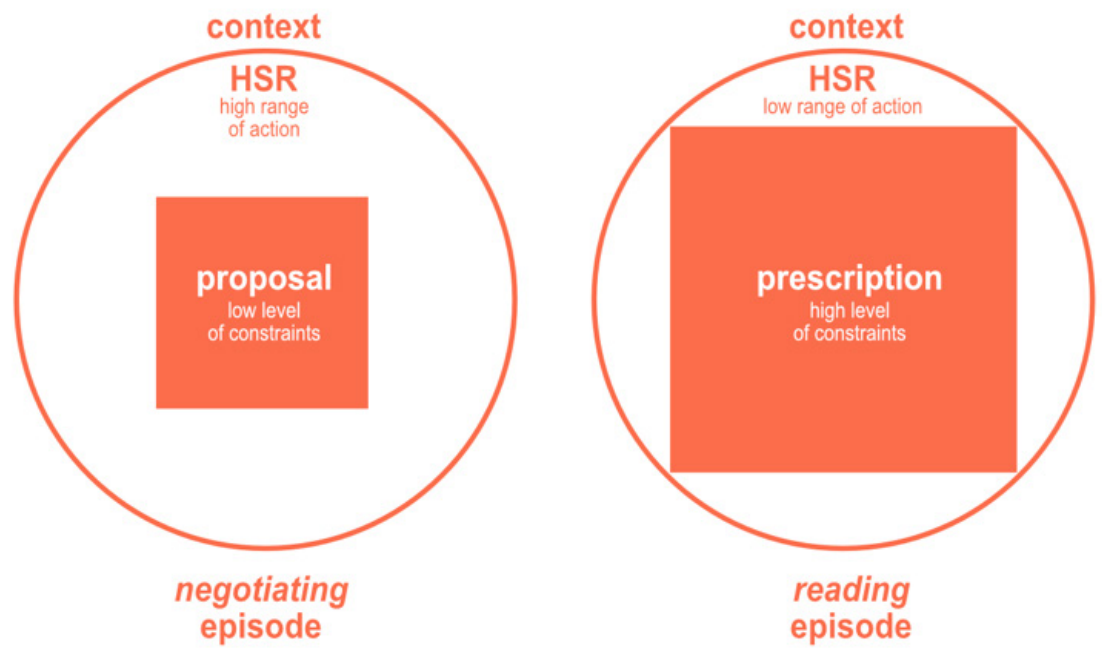

Figure 4. Negotiating and Reading Episodes, Eckert, J., 2017

The second episode, instead, represents a well-defined artefact that consequently comes with certain constraints (e.g. ready product). The number of contexts in which the artefact may fit is limited, and within its HSR it provides a much lower range of actions. The artefact is less agile in this case similar to a prescription or score that allows users to read it while having a limited influence on the way it is interpreted.

Part of the examinations that have led to the concept of $H S R$ refer to critic Umberto Eco's concept of the Opera Aperta [8]. The Opera Aperta embraces human artefacts or creations (such as artworks, musical compositions, performances ect.), which are qualified by their incompleteness. The fact that these creations are not finally defined, gives them an additional openness towards the beholders perception, interpretation or use. Compared to a complete artefact or product, the Opera Aperta has the capacity of being re-created each time a new beholder or user starts interacting with. The momentary aspect of Eco's Opera Aperta which emanates from the fact that it aims at future recreations not only opens the entire process of creating "open works" towards future co-creators but also to the aspect of time [17: p.35]. From an economic and corporate point of view, this timeless exposure of an artefact to future interpretation or even misinterpretation often is associated with a loss of control over the products quality over a certain period [18: p.61, 81, 89]. From a design point of view instead, an ongoing re-interpretation of an artefact or product certainly is linked to the potential of future innovation. In their paper "Incomplete by Design and Designing for Incompleteness" [19] Raghu Garud, Sanjay Jain and Philipp Tuertscher argue for such an ongoing process of design and innovation by stating: "At one level, incompleteness serves as a trigger for the creation of many diverse ideas on how a design can be extended and further developed. At another level, engagement with such a system both transforms the design as well as creates new avenues for ongoing engagement which, in turn, attracts a new set of contributors who bring into the fold their own contextualized needs, purposes and goals." [19: p. 358].

\section{Second Hypothesis: The Antifragile - Embracing the Uncertain}

Closed innovation processes tend towards meeting disturbance with a high level of robustness to preserve their original output. Open Innovation instead, has the possibility to meet disturbances with an ability to adopt, modify and transform or mutate. According to the first hypothesis made in this paper, each mutation in time might lead to an evolution of the product. The second hypothesis emphasizes this evolutionary perspective by taking into consideration that each disturbance of an artefact or process provides potential for innovation and turns the overall relationship between designers, artefacts and users into a resilient or antifragile system. Philosopher and essayist Nassim Nicholas Taleb puts this particular way to meet disturbance into the following words: "Antifragility is beyond resilience or robustness, the resilient resists shocks and stays the same; the antifragile gets better." [6: p.17].

While most systems try to become more resistant against external disturbance, they also take the risk to get stuck in the procedure of maintaining a high level of closedness and control. In the case of innovation processes this might also lead to a decrease of the potential to generate innovative output. The reason why many companies tend towards doing so is that first and foremost disturbance and incompleteness are defined as something negative. In his definition of the antifragile, Taleb states that the antifragile loves randomness and uncertainty, which also means - crucially - "a love of errors, a certain class of errors" [6: p. 17]. This positive attitude towards failing is something that at the first glance might appear contradictory and counterproductive when talking about Innovation. 
While talking about "Innovation Triggers", Barry Wylant [20] examines Teresa Amabile's framework for creativity [21], where he describes the "willingness to take risks" [20: p.5] as one of the relevant aspects for creativity. This willingness or preparedness to meet the unknown and uncertain relates very well to the way Taleb describes one of the advantages of the antifragile. It further also relates to the concept of Handlungsspielraum and the role of the incomplete exposed in the first hypothesis. Consequently both, the uncertain and the incomplete might work as triggers for Innovation when embedded into a process with the appropriate openness towards any sort of disturbance.

Key to this appropriate openness is Taleb's examination of systems while meeting disturbances on a long-term scale. According to him [6: p.21-22] robustness (as resilience as well) calibrates a system by taking into consideration the most likely and most frequent disturbances. Irregular events which are very unlike to happen are mostly not considered when creating robust or resilient systems. Taleb calls these improbable events or disturbances "Black Swans" [22;6: p.18] since they compare to something we would never think of, that we would never expect. Consequently, our capability to deal with these extraordinary events is rather low compared to frequent stressors we are exposed to. Now Taleb's proposition to meet such unlikeable events as "Black Swans" is the antifragile systems' ability to evolve and get better every time when clashing with a problem or disturbance. Just as the immune system which gets stronger by building up antibodies when getting stimulated by a virus or a germ [6: p.364].

By transferring Talebs concept to Open Innovation processes and considering the first hypothesis of Handlungsspielraum, the answer to the question on what the openness of innovation processes should be based on, is the readiness to accept the uncertain and the incomplete as a challenge as well as acquire the ability to learn from these disturbances - or in Taleb's word's "How do you Innovate? First, try get into trouble!" [6: p.55].

\section{Case Study - German and Italian Motorcycles}

Due to their literally open construction, motorcycles provide users the possibility to modify a much larger number of components than cars. For instance, you can improve the performance of the engine by modifying certain parts of it or today, you can even modify the motorcycle's software to do so. Further, you can add or substitute many different parts of the bike which would add or change certain other aspects such as, comfort, security, the ability to carry luggage etc. Following the logics of the two hypotheses made, a motorbike will always represent a certain incompleteness regarding the needs of its users.

In certain cases, the bike manufacturers deal with this incompleteness by offering a variety of optional parts which perfectly fit the original bike and customers may add them directly by configuring their motorcycle before buying it. Often, a bike manufacturer would team up with other companies too, to assure any of the other companies' parts would perfectly fit the original bike. At first, this procedure appears to offer certain openness to the customers but in fact by taking control over the availability and quality of the single parts, the company creates a closed system after all. And consequently, customers must buy either the original company's parts or those produced by the authorized suppliers. All this happens because the original manufacturer wants to assure that the overall system between the bike and its parts works in a perfect manner. By opening this system, the company would lose this control over the quality of their product [18] and expose it to disturbance or the uncertain. The described situation is what happens, when e.g. a well-known German manufacturer decides to launch a new series of motorbikes.

The German company's strategy aims at a minimum chance of clashing with stressors or disturbances of their system. Consequently, the openness of their system is limited to a certain level (Fig. 5). Regular stressors excluded by the German's system could be e.g. safety regulations harmed by an additional part which is not exclusively produced by themselves or one of their contractors. It further could be also a malfunction of the motorbike caused by a modification of the bike by adding low quality parts. By applying Taleb's theory of the Black Swan $[22 ; 6:$ p.18] though, any other disturbance which is not taken into consideration by the manufacturer's quality management would have quite a deep impact onto the products entire system. At the same time, any improvement of the motorbike or its parts must be developed or approved by the company itself. The overall potential for spontaneous and further innovation is rather low in this context since all knowledge and resources remain inside the system. 


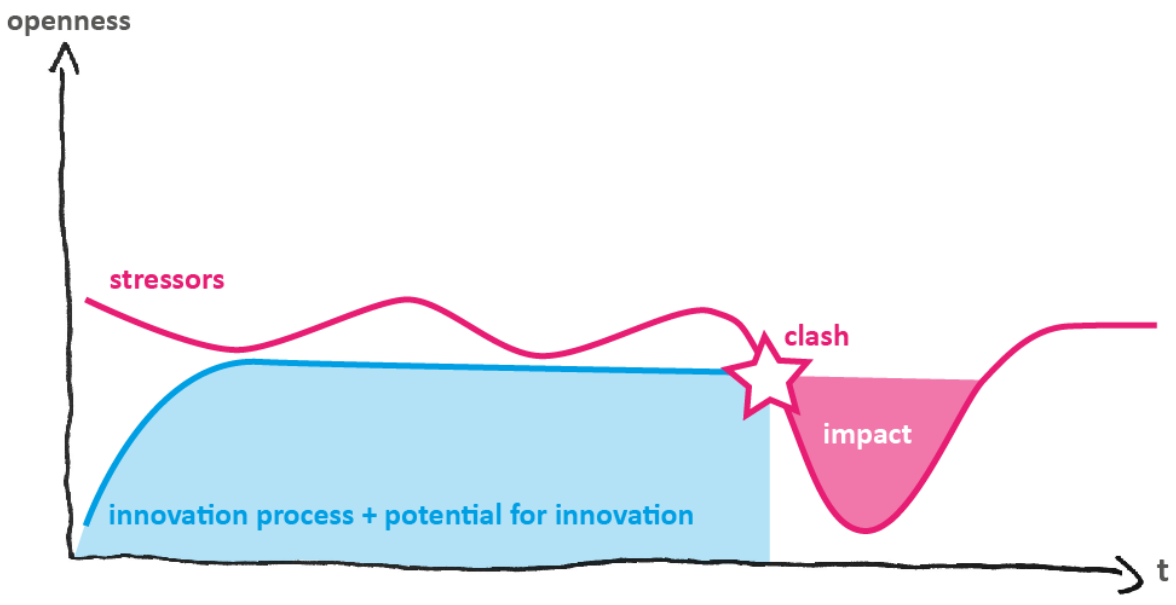

Figure 5. The company-driven and controlled process of the German manufacturer

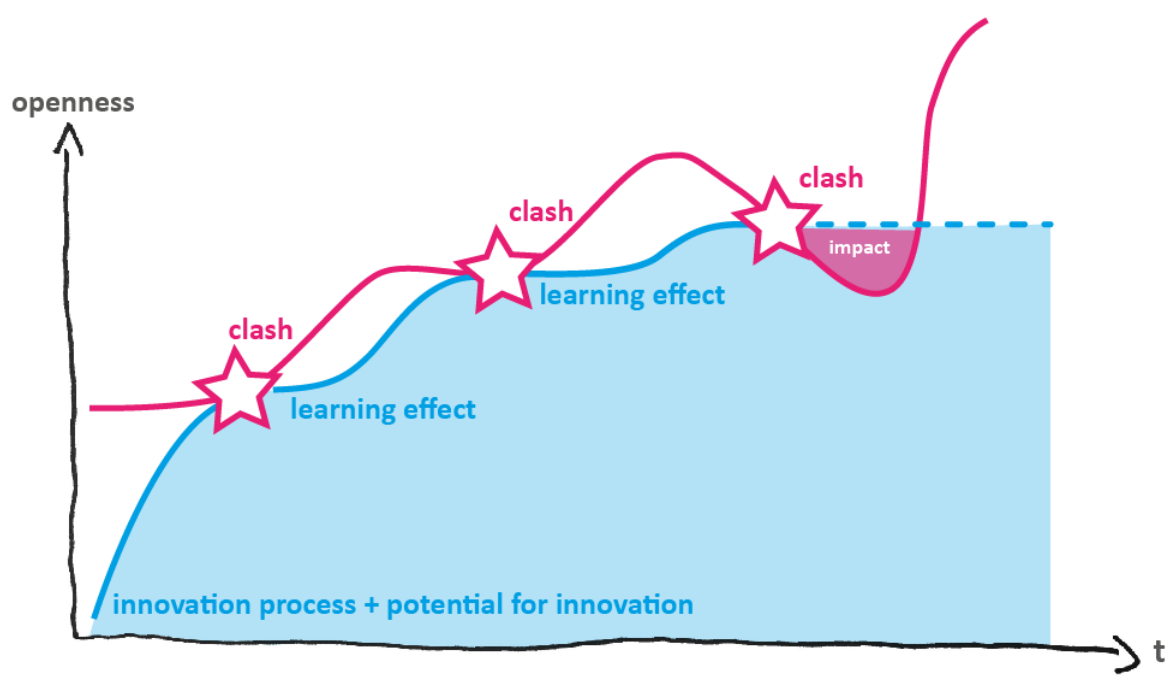

Figure 6. The antifragile process of the "Italian users"

A counterexample to the German motorcycle manufacturer is the way, smaller brands meet the challenge of innovation within their limited range of action. A couple of years ago, it happened to the author to buy a motorbike manufactured by a very small Italian brand. Consequently, the offer of complementary parts on the market is remarkably low compared to the one described in the German case. And each time he wants (or needs) to change a part of his motorbike, it becomes quite a struggle to find the matching one. At the first glance the Italian bike must appear as quite a closed system and the product or offer doesn't seem to be perfect at all. But for once perfection doesn't matter that much, when you're passionate about something. (especially when talking about an Italian 1.2 liter V2 engine). Furthermore, according to the first hypothesis made in this paper the incompleteness of this product might also stimulate the interaction between this product and its user.

And in fact, even though the offer of different bike parts is rather small on the one hand and the problems and malfunctions the author has experienced with his bike are rather frequent on the other one, the level of interaction between him and the motorbike increases with each quest for the solution of a problem. Within this enduring quest, every time defect or disturbance appears, which has been resolved before, the author instantly knows how to deal with it. Consequently, the more problems and defects are offered by the system of his bike, the more he becomes an expert to deal with these problems. Or in Thaleb's words: his attitude of using, getting frustrated, then fixing and modifying his bike makes the entire experience become more and more antifragile [16]. And by doing so, future defects or stressors are less and less likely to have dramatic impacts onto the overall system and relationship between the user and the artefact (Fig.6).

But the Italian case gets even more interesting. Even though it is a quite small motorcycle company, there is a large community of people sharing the same passion for this particular brand. And since all of them are exposed to the same incompleteness of the product, they all act in the same antifragile way to deal with the situation. The more 
customers ride their motorcycles produced by the same brand, the more every one of them acquires a lot of knowledge about the motorbike. Now, since the small company hasn't set up a large enough service network yet, its customers decided to put up an internet forum to share their knowledge. And by doing so, suddenly the entire system opens and becomes a real Open Innovation platform. For instance, some experts in welding developed new frames for the bike. Others acquired knowledge about the bike's electronics and provide instructions how to improve the motorcycle's lighting. Others again by being experts in programming wrote a series of new software for the bike's electronic injection system. And suddenly users have the choice between software which would contribute to a low consumption or others that would improve the power and performance of the motorbike.

$\mathrm{Al}$ in all, a vast number of improvements all together evolved from the uncertainness caused by a rather incomplete product. This happened thanks to the user's decision to act in a collective and antifragile way. Obviously, there is a lot of internet forums about German motorbikes too, but the stimulus to develop new solutions on top of a perfect (and complete) system is rather low compared to one which is open, incomplete and exposed to stressors caused by its originally fragile system.

\section{The Agile Artifact - Designing the Incomplete, Embracing the Uncertain}

Even though the level of openness varies a lot comparing the two companies, both, the German and Italian manufacturer deal with the same incompleteness of their product - just that each has found a different approach to deal with it on a long-term scale. While the German case mostly relates to the reading episode discussed in the first hypothesis of this paper (Fig. 4), the Italian one clearly (even if not intentionally) relates to the negotiating episode. In fact, most design artefacts refer to one or the other episode (or both). Especially, an author-driven era of industrial design has provided many artefacts that refer to the reading episode.

However, the agility described by Thaleb's concept of the Antifragile and the behavior of the Italian user demonstrates that there is something beyond the two episodes described in the first hypothesis. In fact, a lot of potential for innovation emerges when combining the negotiating episode and reading episode into one integrative episode called the staging episode (Fig. 7) [7]. At the core of the staging episode stands the Agile Artefact [7]. Other than common open or iterative design (and innovation) approaches, the Agile Artifact doesn't focus the design process, but promotes an agile outcome instead. Furthermore, it is not necessarily aiming at completeness: for the Agile Artifact "rather than pose a threat, incompleteness acts as a trigger for action" [19: p.352] and in an antifragile way it embraces uncertainty as its biggest strength which triggers future mutations of the artefact.

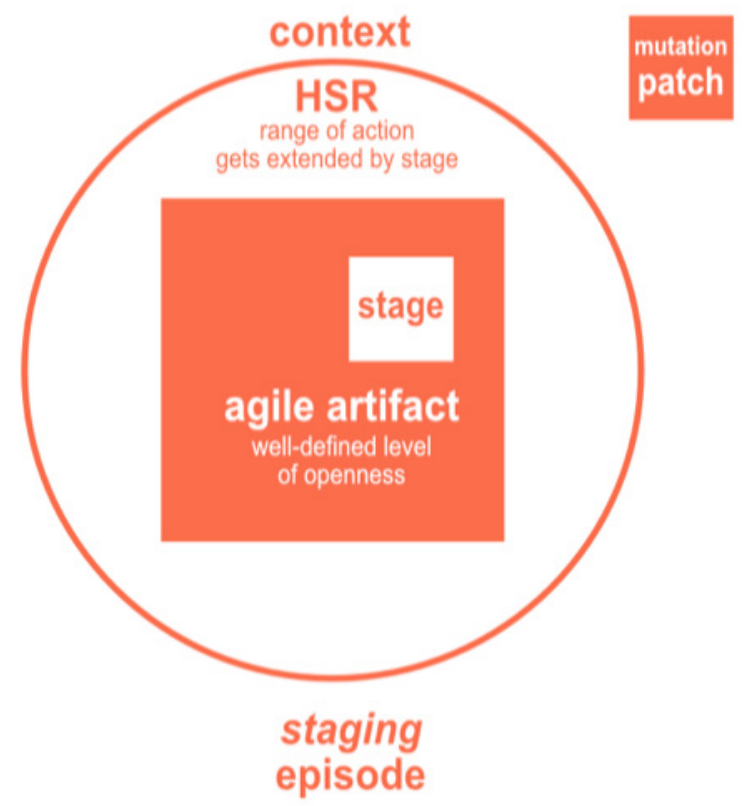

Figure 7. Staging Episode and the Agile Artifact, Eckert, J., Eckert, D., 2017

Compared to the two motorcycle manufacturers' innovation approach, the Agile Artifact includes both, a high level of control over the artefact's quality and constraints, as well as an extension of the range of action, which is called the stage. The stage provides an intentional gap for future mutations (or patches as e.g. in Open Source; [23]). Thanks to this stage and its mutations the Agile Artifact represents a certain permeability and thus, gains a high level of agility. On a long-term base the recurring mutation of the Agile Artifact relates much to the antifragile process discussed in the second hypothesis and the Italian case (Fig. 6). The fundamental difference is that the Agile Artifact's antifragility is not necessarily based upon disturbance or clashes. It rather implies any sort of mutation - deliberate or caused by external impact.

\section{Conclusions}

This paper set out to investigate open design and innovation processes by discussing two hypotheses. The first one suggests incompleteness as trigger for action and innovation, the second investigates the Antifragile, which includes uncertainty and disturbance as additional triggers for improvement and innovation. Both hypotheses relate to most artefacts and products, as well as innovation processes - be it in the design domain or from an economic point of view. Two of such cases have been illustrated in this paper.

As a (deliberately open) conclusion the Agile Artifact proposes an alternative to re-think openness in design and innovation. Other than many approaches, the Agile Artifact does not only focus the innovation process before the 
artefact's launch as a product, but continues its open approach by including incompleteness. Thanks to this incompleteness the Agile Artifact aims at triggering future mutations and re-interpretations - all together summarized in an open, continuous, collective and innovative process. A process that in Taleb's words might be called antifragile or in the words of Italian composer Luciano Berio [24] a journey:

"I think a work always stays there. Because I don't believe that in any form of creativity - be it science, in music, in literature, in painting - there are separate entities, objects. Certain works take shape because something else happened before. There is continuity. It is like a journey. And these works simply are signals in the moment of this journey - but the journey continues."

\section{REFERENCES}

[1] Schuler, Douglas. Namioka, Aki. Participatory Design, Principles and Practices. Hillsdale, NJ: Erlbaum. 1993

[2] Sanders, Elizabeth B.-N.. Stappers, Pieter Jan. Co-Creation and the New Landscapes of Design. CoDesign 4, no. 1: 5-18. 2008

[3] Avital, Michel. The generative bedrock of open design, in: Open Design Now: Why Design Cannot Remain Exclusive. BIS Publishers. 2011

[4] Anderson, Chris. Makers: The New Industrial Revolution. New York: Crown. 2012

[5] Eckert, Jan. New Playdecks for Location Based services. Doctoral Thesis submitted to the School of Doctoral Studies in Design Science at the IUAV University of Venice. 2012

[6] Taleb, N.N. Antifragile, Things That Gain From Disorder, Random House, New York. 2012

[7] Eckert, Jan. Eckert, Daniel. Agile Artifacts - Designing the Imperfect, paper presented at the College Art Association CAA Conference 2017 in New York, USA. 2017

[8] Eco, Umberto. Opera Aperta. VIII edition. Tascabili Bompiani, Nov.2009. 1962.
[9] Caillois, Roger. Les jeux et les hommes, Gallimard, Paris. 1958

[10] Gibson, James J. The Theory of Affordances. In: Perceiving, Acting, and Knowing: Toward an Ecological Psychology, Shaw, R.; Bransford, J.; Lawrence Erlbaum Associates Publishers, Hillsdale, New Jersey; 1977, pp. 127. 1977

[11] Norman, Donald A. The psychology of everyday things and The Design of everyday Things. (2002 Edition at Basic Books). 1977

[12] Norman, Donald A. The Design of Future Things, pp. 67-68. 2007

[13] Bonsiepe, Gui. Entwurfskultur und Gesellschaft. Birkhäuser, Basle, Boston, Berlin. p.114. 2009

[14] Simon, H. A. The sciences of the artificial, 3rd edn. Cambridge, MA: MIT Press. 1996

[15] Brandes, Uta. Non Intentional Design. In: Wörterbuch Design. Begriffliche Perspektiven des Design. Ed. Erlhoff, Michael. Marshall, Tim. Basle, Boston, Berlin. p. 291-293. 2008

[16] Brandes, Uta. Stich, Sonja. Wender, Miriam. Design by useThe everyday Metamorphosis of Things. Birkhäuser, Basle, Boston, Berlin. 2009

[17] Morelli, N. Social Innovation and New Industrial Contexts: Can Designers «Industrialize» Socially Responsible Solutions. In Design Issues, MIT, Vol. 23, No. 4 (autumn 2007), 3-21. 2007

[18] Von Hippel, E. Democratizing Innovation, MIT Press. 2005

[19] Garud, R.; Sanjay, J.; Tuertscher, P.; Incomplete by Design and Designing for Incompleteness, Organization Studies; 29(03): 351-371. 2008

[20] Wylant, B. Design Thinking and the Experience of Innovation in Design Issues, MIT, Vol.24, No. 2 (Spring 2008), 3-14. 2008

[21] Amabile, T. The social Psychology of Creativity, New York Springer-Verlag, 67-70. 1983

[22] Taleb, N.N. The Black Swan: The Impact of the Highly Improbable, Random House, New York. 2008

[23] Raymond, E. The Cathedral and the Bazaar. In: Knowledge, Technology \& Policy, Fall 1999, Vol. 12, No. 3, pp 23-49. 1999

[24] Berio, Luciano. $59 \mathrm{~min}$. video. A portrait of the Italian composer Luciano Berio. Directed by Reuven Palgi-Hecker. 2000 